\title{
Fault Ride-Through Capability Enhancement for Microinverter Applications
}

\author{
Sajad Arab Ansari $\mathbb{D}^{1},{ }^{1}$ Amir Reza Mizani ${ }^{D}{ }^{2}$, \\ Siamak Ashouri $\mathbb{D}^{3}{ }^{3}$ and Javad Shokrollahi Moghani ${ }^{1}$ \\ ${ }^{1}$ Department of Electrical Engineering, Amirkabir University of Technology, Tehran, Iran \\ ${ }^{2}$ Department of Electrical Engineering, Iran University of Science and Technology, Tehran, Iran \\ ${ }^{3}$ Department of Electrical Engineering, Sahand University of Technology, Sahand, Iran \\ Correspondence should be addressed to Sajad Arab Ansari; sajadarabansari@gmail.com
}

Received 20 December 2018; Revised 2 January 2019; Accepted 14 February 2019; Published 7 March 2019

Academic Editor: Shuhui Li

Copyright ( 2019 Sajad Arab Ansari et al. This is an open access article distributed under the Creative Commons Attribution License, which permits unrestricted use, distribution, and reproduction in any medium, provided the original work is properly cited.

Due to the fast growth of single-phase grid-connected photovoltaic (PV) systems, the existing grid codes are expected to be modified to guarantee the availability, quality, and reliability of the electrical system. Therefore, the future single-phase PV systems should become smarter and support low voltage ride-through (LVRT) capability, which are required for three-phase wind power systems. In this paper, the operation principle of a flyback inverter in a low-voltage ride-through operation is demonstrated in order to map future challenges. The steady state performance of the flyback inverter under voltage rise and drop conditions at boundary conduction mode (BCM) and discontinues conduction mode (DCM) is studied theoretically. The simulation results of the flyback inverter for various grid faults are presented to verify the theoretical analyses. The results indicate the fact that the flyback inverter at BCM condition can provide LVRT capability for photovoltaic microinverter applications in distributed generation (DG) systems, even though it does not need any auxiliary control branches and any limitations in components design.

\section{Introduction}

Recently, due to the matured PV technology and the declined cost of the PV module cells, the use of single-phase gridconnected PV systems has increased in the public grid [1,2]. PV power systems can be categorized into centralized, string, and AC module systems. The use of a microinverter, which is also named AC-PV module, is becoming more popular due to its important benefits compared to the conventional centralized architecture. The AC-PV module which is shown in Figure 1 has numerous merits, namely, higher efficiency, individual maximum power point tracking (MPPT), alleviating the negative effects of partial shading, higher reliability and flexibility, friendly "Plug-N-Play" operation, and simple installation of modules [3-6]. The microinverter consists of a single PV module and a single-phase inverter ranging from $50 \mathrm{~W}$ to $400 \mathrm{~W}$. Therefore, these small scale systems can be forthrightly deployed in urban low voltage DG systems with relatively simple technical efforts and without occupying productive land and/or deteriorating urban environments. Nevertheless, the phenomenon of large scale DG systems which are connected to the public network increases some significant alarm about the availability, quality, and reliability of the public network.

Traditionally, since the grid-connected PV distributed generation systems were small scale at a residential level, they were designed to be disconnected from the grid under voltage rise and drop conditions in order to protect the interfacing inverter [7]. However, because of the increasing penetration of grid-connected PV systems in the public grid, not only can the disconnection of a large power grid-connected PV systems disturb the stability of the main grid but also it can cause detrimental influence on the quality, availability, and reliability of the whole system. Accordingly, many grid requests are proposed for DG systems recently to control the interaction between DGs and the public network $[8,9]$. The fact that the future grid-connected PV systems will be smarter to provide the LVRT capability is expected [9, 


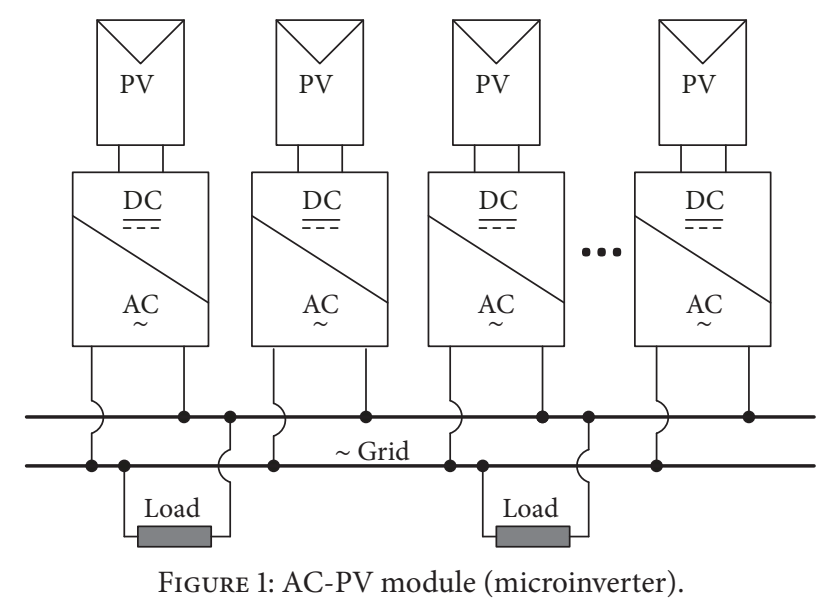

10]. The LVRT capability needs that the generation system remains connected to the grid in order to help the grid voltage and frequency remain stable during the grid faults. On this basis, a lot of research has been done on the gridconnected PV systems so that they provide LVRT capability [11-14]. Also, various developments related to this concern have been already done for wind farms [15-18], since they provide higher power in comparison to the photovoltaic systems which are connected to the grid.

It is common that the LVRT capability generally is used in medium-voltage networks. Because of the rapid rising of single-phase grid-connected PV systems, this feature is extended in DG units installed in the low-voltage networks. In [19-23], some investigations on the single-phase gridconnected PV systems have been presented in order to prove that the LVRT capability can be achieved. These papers studied various aspects of LVRT control strategies which include sequence separation techniques, phase locked loop (PLL), current controller, and control approaches. A vector current control technique which uses negative sequence voltage feed forward is introduced in [1] to enhance the single-phase inverter performances under various grid faults. A through control strategy which allows the PV power plant to tolerate grid faults is proposed in [24]. Not only is the ac over-current as well as the dc-link over-voltage limited during voltage rise and fall, but also reactive power is injected in gird. However, since the control techniques in previous works are based on the concept of single-phase active and reactive power or the frequency and voltage droop control through active and reactive power, respectively, the complexity as well as cost of the control system of the grid-connected PV systems surges.

The aforementioned benefits of the microinverters and growing their power ranges make them a significant factor in the growth of the penetration of PV systems. Moreover, the microinverters are used in $5-10 \mathrm{~kW}$ building PV applications since they provide higher energy in comparison with the centralized architecture of PV systems. Hence, in the future, the microinverters will be a significant part of the PV systems at the urban low-voltage networks; thus, they should be smarter and support LVRT capability to enhance the stability and reliability of the grid [25-27].
The various inverters which can be employed in singlephase grid-connected PV application are reviewed in [3, 28]. Among the numerous topologies, flyback inverter is widely used in microinverters because it has many advantages such as simple configuration, low manufacturing cost, high efficiency, no DC-DC step-up converter, and isolation between the input source and public grid [29-31]. Hence, the flyback inverter should be modified to support the LVRT capability. In [26], the LVRT capability is implemented on the microcontroller so that the flyback microinverter remains connected to the grid during some prespecified voltage sag limits. In this topology, an auxiliary control branch is added to the main control system of the flyback inverter to support the LVRT capability which causes complexity of the control system and high manufacturing cost. Also, the inverter cannot support LVRT for various ranges of voltage sag. In [25], the LVRT capability for the flyback inverter is provided at DCM condition. Nonetheless, it suffers from some shortcomings, namely, numerous limitations for designing of the inverter's components, low quality, and low reliability under deep grid faults. Also, the THD analysis is missing in it and from its results, it seems that the THD is high during the voltage fault.

In this paper, the performance of the flyback inverter for microinverter applications is studied. The complete operation of the flyback inverter at BCM and DCM operations under voltage rise and drop conditions is presented. It will be indicated that the flyback inverter at BCM condition can provide LVRT capability, despite the fact that it does not need any auxiliary control branches and any limitations in components design of the inverter. Also, the output current THD is in appropriate range during voltage fault. The control system of the flyback inverter at BCM condition is simple since it only needs an open-loop control technique. The overall control system of the flyback microinverter based on the grid requirements which have been already defined for wind power systems while public grid is under faulty mode condition is presented. It is predicted that these requirements for wind power systems will be the basic requirements for grid-connected PV distributed generation systems. Finally, the unique feature of the flyback inverter at BCM condition under various grid faults is verified by simulation results.

The paper is organized as follows. In Section 2, there is an overview of selected grid requirements. The analysis of the flyback inverter at BCM condition is presented in Section 3. In Section 4, the analysis of the flyback inverter under voltage rise and drop conditions is discussed. In Section 5, design considerations of the flyback inverter at BCM condition are obtained. In Section 6, the simulation results of the flyback inverter at BCM and DCM operations under various grid faults are presented. Finally, a brief conclusion is provided in Section 7.

\section{Grid Requirement}

In some international regulations [32], it is mentioned that the grid-connected photovoltaic DG systems at a residential level have to be disconnected from the grid to protect the interfacing inverter. In these grid requirements, the basic 


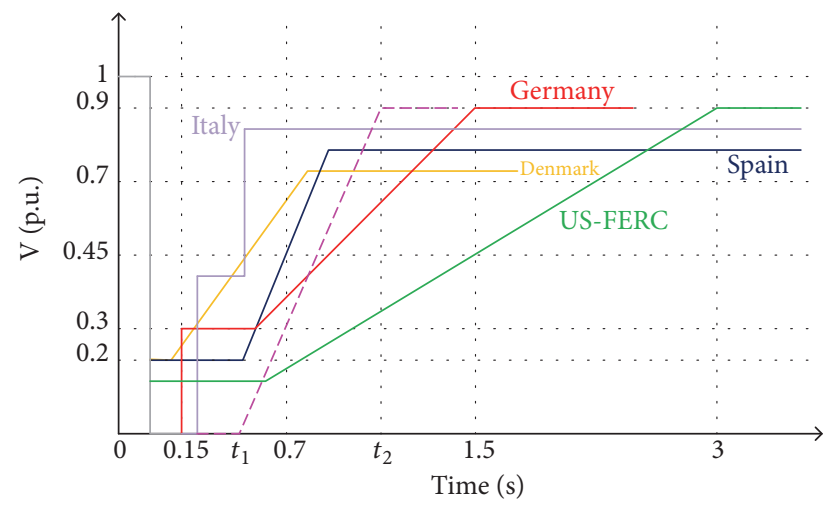

FIGURE 2: LVRT requirements of DG systems for various countries.

demands are imposed such as the power quality of the gridconnected inverter (the output current THD) and the antiislanding condition. However, because of the fast growing installations of single-phase grid-connected PV systems, the grid requirements for DG systems are updated and modified based on the growth and penetration level of grid-connected photovoltaic DG systems. Like wind power systems which are connected to the medium and high voltages of the public grid, the future single-phase grid-connected PV systems should provide a contribution to the public grid by means of riding through grid faults, which is known as LVRT capability.

The LVRT capability is implemented in order that the DG system should remain connected to the grid for a short transition time and help the grid voltage and frequency stay stable during the public grid faults. Figure 2 depicts the various LVRT curves, derived by studying several energy markets, with defined remain-connected time under various grid faults which is named grid code $[8,33]$. According to Figure 2, correspondingly to the depth of the voltage drop, the required time duration where DG system should remain connected to the grid is between $t_{1}$ and $t_{2}$. For instance, if the grid voltage falls to $O V$, the DG unit should remain connected to the grid for 0.15 seconds in the German grid code. Also, under voltage rise condition, the DG unit operates in normal condition. These grid codes are provided to guarantee the safety of utility maintenance personnel and equipment of the microinverter and to avoid the grid collapse because of grid faults.

\section{Analysis of the Flyback Inverter at BCM Condition}

The flyback inverter can operate with its magnetizing current in continuous conduction mode (CCM), DCM, or BCM. In the flyback inverter, CCM operation requires a complex control system since the transfer function of the inverter in this mode has a right half plane (RHP) zero. However, DCM and BCM operations are simply achieved by peak-current control $[34,35]$. In addition, a hybrid operation which mixes DCM and BCM operations in a half grid period has been adopted to enhance the efficiency and diminish the output current THD of the inverter [36,37].

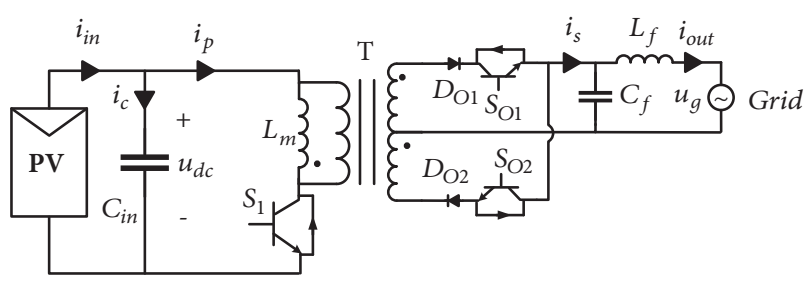

(a)

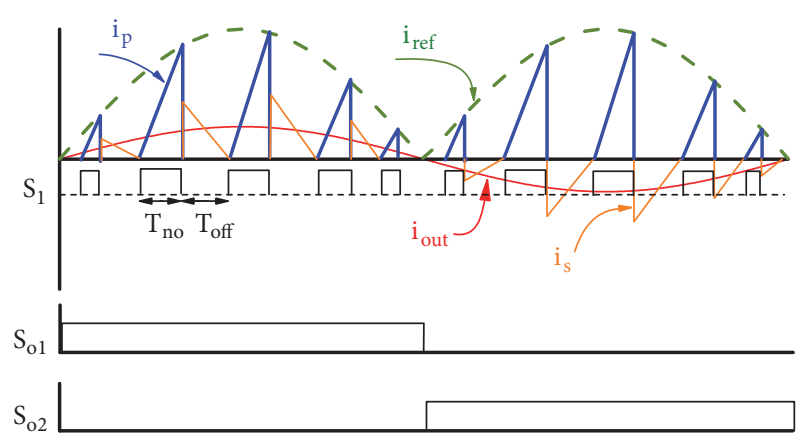

(b)

FIGURE 3: Flyback microinverter. (a) Schematic. (b) Key waveforms at $\mathrm{BCM}$ condition.

The schematic of the flyback inverter and its key waveforms under BCM condition are presented in Figures 3(a) and 3(b), respectively. As shown in Figure 3(a), the flyback inverter includes one high frequency switch $S_{1}$, input capacitance $C_{i n}$, a high frequency transformer $T$ with two secondary windings, two low frequency switches in the secondary $S_{o 1}$ and $S_{o 2}$, two secondary diodes $D_{o 1}$ and $D_{o 2}$, and output filter including a capacitor $C_{f}$ and an inductance $L_{f}$. The turns ratio of the primary to the secondary winding is $N_{p}: N_{s}$, and the magnetizing inductance of the transformer is $L_{m}$.

At BCM condition, the output current $i_{\text {out }}$ can be directly controlled by the primary reference current $i_{r e f}$ in each switching period. The gating pulses as well as current waveforms of the switches of the flyback inverter are depicted in Figure 3(b). From Figure 3(b), it can be observed that the pulse width of the main switch is created in a Sine Pulse Width Modulation (SPWM) pattern to generate a sinusoidal output current. When the main switch is turned on, $L_{m}$ is charged by the input voltage source. Then, the main switch is turned off and the energy stored in $L_{m}$ is transferred to the grid by the one of the secondary diodes. Under BCM condition, the main switch $S_{1}$ is turned on when the current of the magnetizing inductance drops to zero. Also, the secondary switches $S_{o 1}$ and $S_{o 2}$ are turned on in the positive and negative half grid period, respectively, to change the semi-sinusoidal secondary currents of the secondary windings to a full-sinusoidal current.

According to Figure 3(b), the peak value of the primary winding current $I_{p}$ is forced to follow the primary reference current $i_{\text {ref }}$ under BCM operation. In each switching period, when the secondary current $i_{s}$ drops to zero, $S_{1}$ is turned on, and $i_{p}$ rises linearly with $u_{d c}$. When $i_{p}$ reaches $i_{r e f}, S_{1}$ is turned off and $i_{s}$ reduces linearly with $u_{g}$. Finally, the output current 


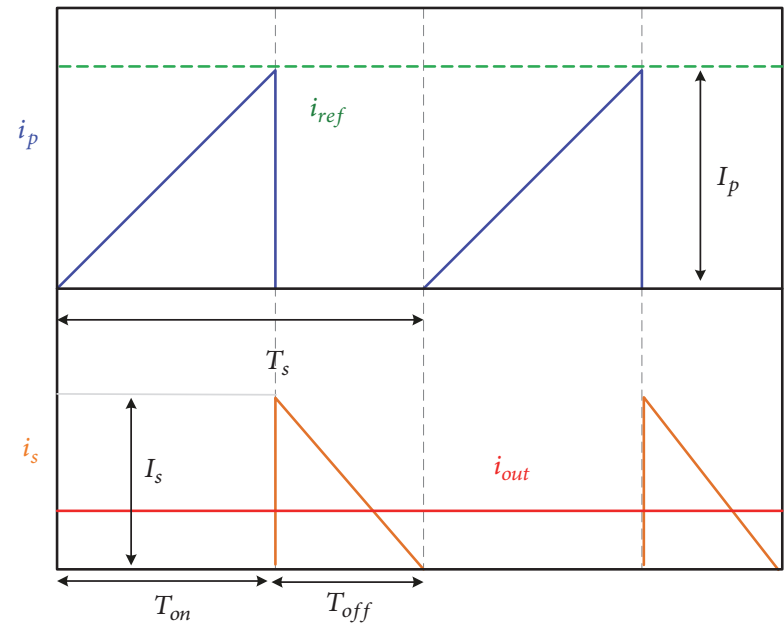

(a)

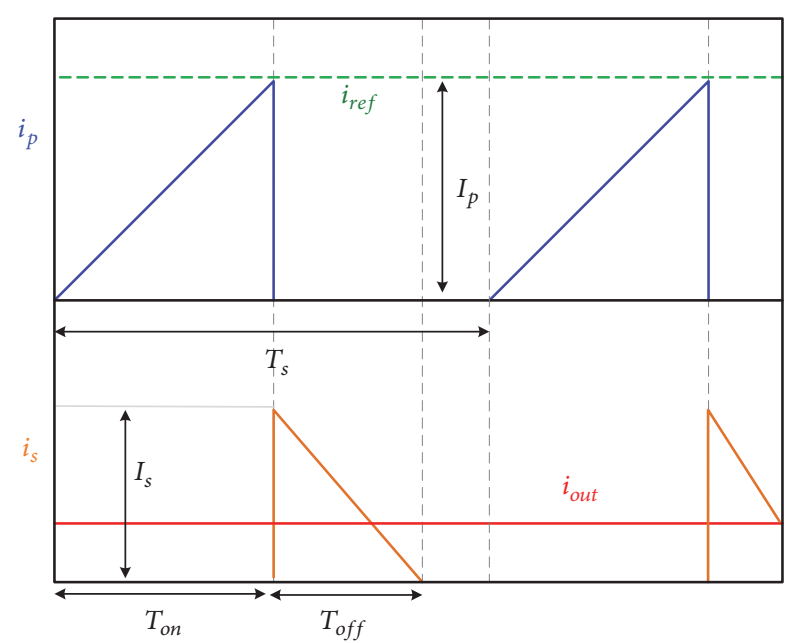

(b)

FIGURE 4: The primary and secondary currents of the flyback's transformer in switching period. (a) Under BCM operation. (b) Under DCM operation.

of the inverter $i_{\text {out }}$ is achieved by filtering the secondary current of the transformer.

In order to make the analysis simple, some assumptions are considered which are presented as follows: (i) All the components are considered ideal. (ii) The inverter operates in steady-state condition. (iii) Both the input and output voltages are constant in each switching cycle. (iv) The grid voltage is positive; thus, $S_{o 1}$ is on and $S_{02}$ is off in the analysis. It is worth mentioning that the operation of the flyback inverter during both the positive and negative half period of the grid voltage is analogous.

The primary and secondary currents of the flyback inverter in switching period under BCM condition are presented in Figure 4(a). As shown in this figure, the turn-on time $T_{o n}$ and turn-off time $T_{\text {off }}$ and the switching period $T_{s}$ can be achieved as (1) and (2), respectively. The relationship between the maximum of the primary current in each switching period $I_{p}$ and the maximum of the secondary current in each switching period $I_{s}$ can be defined as (3).

$$
\begin{aligned}
T_{o n} & =L_{p} \cdot I_{p} \cdot \frac{1}{u_{d c}} \\
T_{o f f} & =L_{s} \cdot I_{s} \cdot \frac{1}{u_{g}} \\
T_{s} & =T_{o n}+T_{o f f} \\
I_{p} & =i_{r e f} \\
I_{s} & =\frac{N_{p}}{N_{s}} I_{P}=n \cdot I_{p}=I_{p} \sqrt{\frac{L_{p}}{L_{s}}}
\end{aligned}
$$

Since $i_{\text {out }}$, which injects to public grid, is achieved by filtering $i_{s}, i_{\text {out }}$ is approximately equal to the average value of $i_{s}$ in each switching cycle. Hence, the output current can be achieved as (4).

$$
i_{\text {out }}=\frac{1}{2} \cdot I_{s} \cdot T_{\text {off }} \cdot \frac{1}{T_{\text {on }}+T_{\text {off }}}
$$

According to (1)-(4), $i_{\text {out }}$ can be expressed as (5).

$$
i_{\text {out }}=\frac{1}{2} \cdot \frac{\left(i_{r e f} \sqrt{L_{p} / L_{s}}\right) \cdot\left(L_{s} \cdot i_{r e f} \cdot \sqrt{L_{p} / L_{s}} \cdot 1 / u_{g}\right)}{i_{r e f} \cdot L_{p} \cdot 1 / u_{d c}+L_{s} \cdot i_{r e f} \cdot \sqrt{L_{p} / L_{s}} \cdot 1 / u_{g}}
$$

After simplification, the reference current $i_{\text {ref }}$ is

$$
i_{\text {ref }}=2 i_{\text {out }}\left(\frac{u_{g}}{u_{d c}}+\sqrt{\frac{L_{s}}{L_{p}}}\right)
$$

where

$$
\begin{aligned}
i_{\text {out }} & =I_{A} \sin (\omega t) \\
u_{g} & =V_{p} \sin (\omega t)
\end{aligned}
$$

Substituting (7) into (6), the primary reference current $i_{\text {ref }}$ of a single-phase grid-connected flyback inverter at BCM condition is calculated by $(8)$.

$$
i_{r e f}(w t)=2 I_{A}\left(\frac{V_{p}}{u_{d c}} \sin ^{2}(\omega t)+\sqrt{\frac{L_{s}}{L_{p}}} \sin (\omega t)\right)
$$

\section{Analysis of the Flyback Inverter under Voltage Rise and Drop Conditions}

In Figure 4(b), the primary and secondary currents of the flyback's transformer at DCM condition in some switching period are presented. At DCM condition, according to Figure 4(b), it must be confirmed that the difference between the time interval of the switching period $T_{s}$ and the maximum of the turn-on time interval $T_{\text {on.peak }}$ is higher than the turn-off time interval $T_{\text {off }}$,

$$
T_{\text {off }} \leq T_{s}-T_{\text {on.peak }}
$$




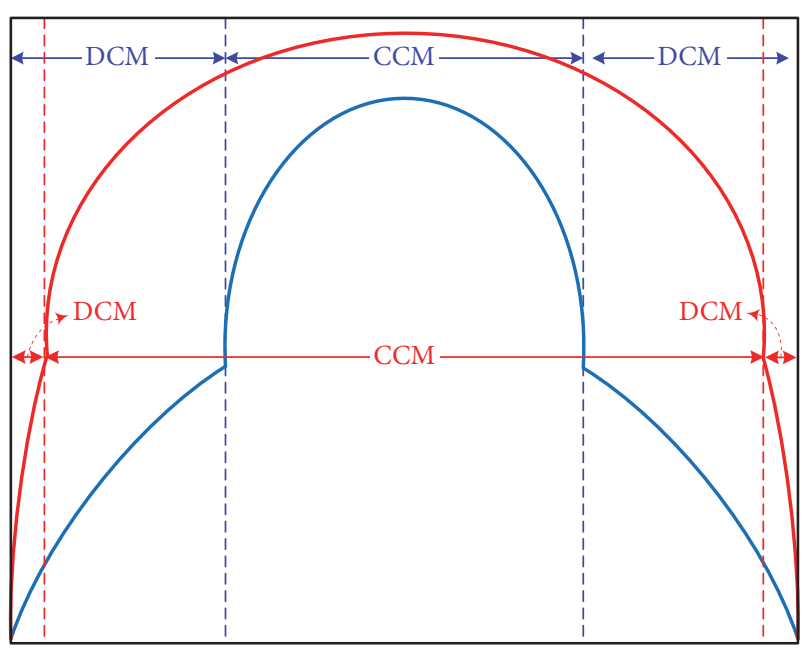

Deep voltage drop
Light voltage drop

FIGURE 5: The output current of the flyback inverter in mixed operation mode.

It can be found from Figure 4 that the turn-off time $T_{\text {off }}$ and turn-on time $T_{\text {on }}$ have the same relations in DCM and BCM operations.

In voltage drop condition, according to the relation (1), the turn-off time interval $T_{\text {off }}$ rises, even though the switching frequency $f_{s}$ and the maximum of the turn-on time interval $T_{\text {on.peak }}$ remain constant. Hence, the condition (9) is not true in this condition. This effect leads the mode of the flyback inverter to the mixed conditions where CCM and DCM operations take place simultaneously during a half grid period. The output current of the flyback inverter at mixed operation under light and deep voltage drop conditions is shown in Figure 5. As shown in Figure 5, the output current during grid period includes numerous harmonics with high amplitude which is very detrimental for the microinverter system. Also, the previous section mentions that the flyback inverter at CCM operation has an RHP in its transfer function, which makes the inverter unstable and distorts the output current. Therefore, the flyback inverter in DCM operation has to be disconnected from the grid under voltage drop condition. Also, according to Figure 5, the flyback inverter at hybrid DCM-BCM operation cannot support LVRT capability under deep voltage drop condition because hybrid switching technique uses DCM operation at the beginning and end of each half line cycle and under deep voltage drop, inverter leads to CCM operation quickly before the operation mode of the inverter converts to BCM operation.

In BCM operation, according to the relation (2) and Figure 4(a), the interval $T_{\text {off }}$ is equal to the time interval between the intervals $T_{s}$ and $T_{\text {on.peak }}$,

$$
T_{\text {off }}=T_{s}-T_{\text {on.peak }}
$$

In BCM operation, according to the relations (1) and (10), since the switching period $T_{s}$ continues until the current of the magnetizing inductance drops to zero, $T_{s}$ is not constant in all switching periods. Hence, if the turn-off time interval $T_{\text {off }}$ surges, the operation mode of the converter does not change and inverter remains under BCM operation and only the inverter switching period $T_{s}$ increases which does not have a detrimental effect on the performance of inverter. In addition, the output current does not rise too much, since the primary reference current is limited by the value specified in the MPPT system. Hence, the flyback inverter at BCM condition can stay connected to the grid under voltage drop condition and support LVRT capability.

In voltage rise condition, at both of the DCM and BCM operations, according to the relation (1), because of the fact that the turn-off time interval $T_{\text {off }}$ reduces, the mode of the flyback inverter does not change. Therefore, under the case of voltage rise, the operation mode of the flyback inverter remains unchanged. Consequently, this paper only concentrates on the case of voltage drop condition.

\section{Parameters Design}

A $200 \mathrm{~W}$ microinverter at $220 \mathrm{Vrms} / 50 \mathrm{~Hz}$ utility condition is designed in this work. The voltage of the PV panel at the maximum power point is equal to $40 \mathrm{~V}$. The design of the flyback inverter's parameters is the same as conventional design procedure of flyback inverter at BCM condition, which is presented as follows.

5.1. Selection of the Magnetic Inductance. The primary inductance $L_{p}$ can be calculated from (11), where, according to [38], $\delta_{\text {max }}$ is the maximum duty ratio of the main switch which is equal to 0.5 and $f_{s}$ is the minimum value of the switching frequency which is equal to $200 \mathrm{kHz}$.

$$
L_{p}=L_{m}=\frac{u_{d c \cdot \min } \cdot \delta_{\max }}{I_{p \cdot \max } \cdot f_{s}}
$$

where

$$
I_{p \cdot \max }=2 I_{A}\left(\frac{V_{p}}{u_{d c}}+\frac{1}{n}\right)
$$

Therefore, the required $L_{p}$ is $4.2 \mu H$. Then, the secondary inductance $L_{s}$ is obtained as (13), where the turns ratio $n$ is $1 / 6$.

$$
L_{s}=\frac{L_{p}}{n^{2}}
$$

5.2. Selection of the Input Capacitor. The flyback microinverter needs a gigantic DC input capacitance $C_{\text {in }}$ to decouple the power pulsation which is caused by single-phase power generation to the utility line [39]. The value of $C_{i n}$ can be calculated by (14) [30]. Since the input voltage ripple $\Delta u_{d c}$ is considered equal to $2 \mathrm{~V}$, the minimum required value of the input capacitor is $8.83 \mathrm{mF}$.

$$
C_{\text {in }}=\frac{P_{\text {in }}}{\omega u_{d c} \Delta u_{d c}}
$$


TABLE 1: Value of the microinverter's components.

\begin{tabular}{lcc}
\hline Symbol & Quantity & Value \\
\hline $\mathrm{u}_{\mathrm{dc}}$ & Input voltage source & $40 \mathrm{~V}$ \\
$\mathrm{~L}_{\mathrm{P}}$ & Primary inductance & $4.2 \mu \mathrm{H}$ \\
$\mathrm{L}_{\mathrm{S}}$ & Secondary inductance & $151.2 \mu \mathrm{H}$ \\
$\mathrm{C}_{\mathrm{f}}$ & Output filter capacitor & $280 \mathrm{nF}$ \\
$\mathrm{L}_{\mathrm{f}}$ & Output filter inductor & $510 \mu \mathrm{H}$ \\
$\mathrm{C}_{\mathrm{in}}$ & DC input capacitor & $8.8 \mathrm{mF}$ \\
$\mathrm{V}_{\mathrm{p}}$ & Voltage of public grid & $220 \mathrm{Vrms}$ \\
$\mathrm{n}$ & Turns ratio of transformer & $1 / 6$ \\
$\mathrm{f}_{\mathrm{o}}$ & Frequency of the public grid & $50 \mathrm{~Hz}$ \\
$\mathrm{P}_{\mathrm{PV}}$ & Power of PV panel & $200 \mathrm{~W}$ \\
\hline
\end{tabular}

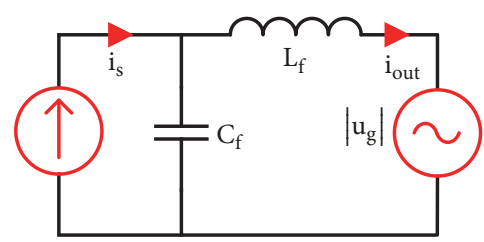

FIgURE 6: Equivalent diagram of the output filter.

5.3. Output Filter Design. The equivalent circuit of the output filter of the flyback inverter is illustrated in Figure 6. According to Figure 6 , the relationship between $i_{\text {out }}, i_{s}$, and $u_{g}$ can be obtained as (15).

$$
I_{\text {out }}=\frac{1}{1+S^{2} L_{F} C_{F}} I_{s}(s)-\frac{S C_{f}}{1+S^{2} L_{F} C_{F}} U_{g}(s)
$$

The expression of the CL filter is

$$
\begin{aligned}
& \left.\frac{I_{\text {out }}(s)}{I_{s}}\right|_{U_{g}(s)=0}=\frac{1}{1+s^{2} L_{f} C_{f}} \\
& \left.\frac{I_{\text {out }}(s)}{U_{g}(s)}\right|_{I_{s}(s)=0}=\frac{s C_{f}}{1+s^{2} L_{f} C_{f}}
\end{aligned}
$$

This is a second-order low-pass filter with a resonant frequency $f_{r}$, which can be defined as (17). In this design, $f r$ should comply with (18) [30]. Finally, $L_{f}$ and $C_{f}$ are selected as $510 \mu \mathrm{H}$ and $280 \mathrm{nF}$, respectively.

$$
\begin{aligned}
f_{r} & =\frac{1}{2 \pi \sqrt{L_{f} C_{f}}} \\
10 f_{o} & \leq \frac{1}{2 \pi \sqrt{L_{f} C_{f}}} \leq \frac{1}{10} f_{s \cdot \min }
\end{aligned}
$$

5.4. Design of the Reference Current. The value of $I_{A}$ which is related to $P_{\text {out }}$ is shown as (19). The input power is $200 \mathrm{~W}$. Therefore, $I_{A}$ is $1.286 A$.

$$
P_{\text {out }}=\frac{I_{A} V_{p}}{2}
$$

Finally, from (8), the reference primary current of the flyback microinverter for the introduced control system is obtained by (20).

$$
i_{r e f}(w t)=2.572\left(7.775 \sin ^{2}(\omega t)+6 \sin (\omega t)\right)
$$

\section{Simulation Results}

To validate the theoretical analyses and show the effectiveness of the flyback inverter at BCM condition for LVRT capability, the simulation results of a $200 \mathrm{~W}$ flyback microinverter under various grid faults are given. The parameters' values which are calculated according to the design procedure mentioned in the section fifth are presented in Table 1.

The schematic of the flyback inverter and its control system at BCM condition is presented in Figure 7. The control system of the flyback inverter at BCM condition is simple since it only needs an open-loop control technique. Inasmuch as the inverter operates at BCM, its switching frequency $f_{s}$ is variable. The frequency and phase angle $\theta$ of the grid are sensed by phase locked loop (PLL). According to the grid voltage, the gating pulses of the secondary switches are created, where $S_{o 1}$ and $S_{o 2}$ are on in the positive and negative half grid period, respectively. The operation of the microinverter under normal condition of the grid in accordance with the grid code is guaranteed by islanding protection. The input energy is achieved by sensing the PV voltage and current in order that $I_{A}$ can be regulated to obtain the MPPT based on the perturbation and observation (P\&O) method [40]. The conventional P\&O algorithm uses fixed step-length, which is realized by adjusting $I_{A}$ as shown in Figure 8.

The output current of the flyback inverter and grid voltage under DCM operation for two different voltage drops (0.6 p.u. and 0.1 p.u.) are depicted in Figure 9. According to Figure 9 , the voltage sag starts at $\mathrm{t}=0.3 \mathrm{~s}$ and continues for $100 \mathrm{~ms}$. The primary current of the flyback inverter in grid period is presented in Figure 10. Also, the details of the primary and secondary currents during voltage fault are shown in Figure 11. According to Figures 9-11, for voltage drop condition, the mode of the flyback inverter leads to the mixed operation where CCM and DCM operations take place in a half grid period. Therefore, the output current 


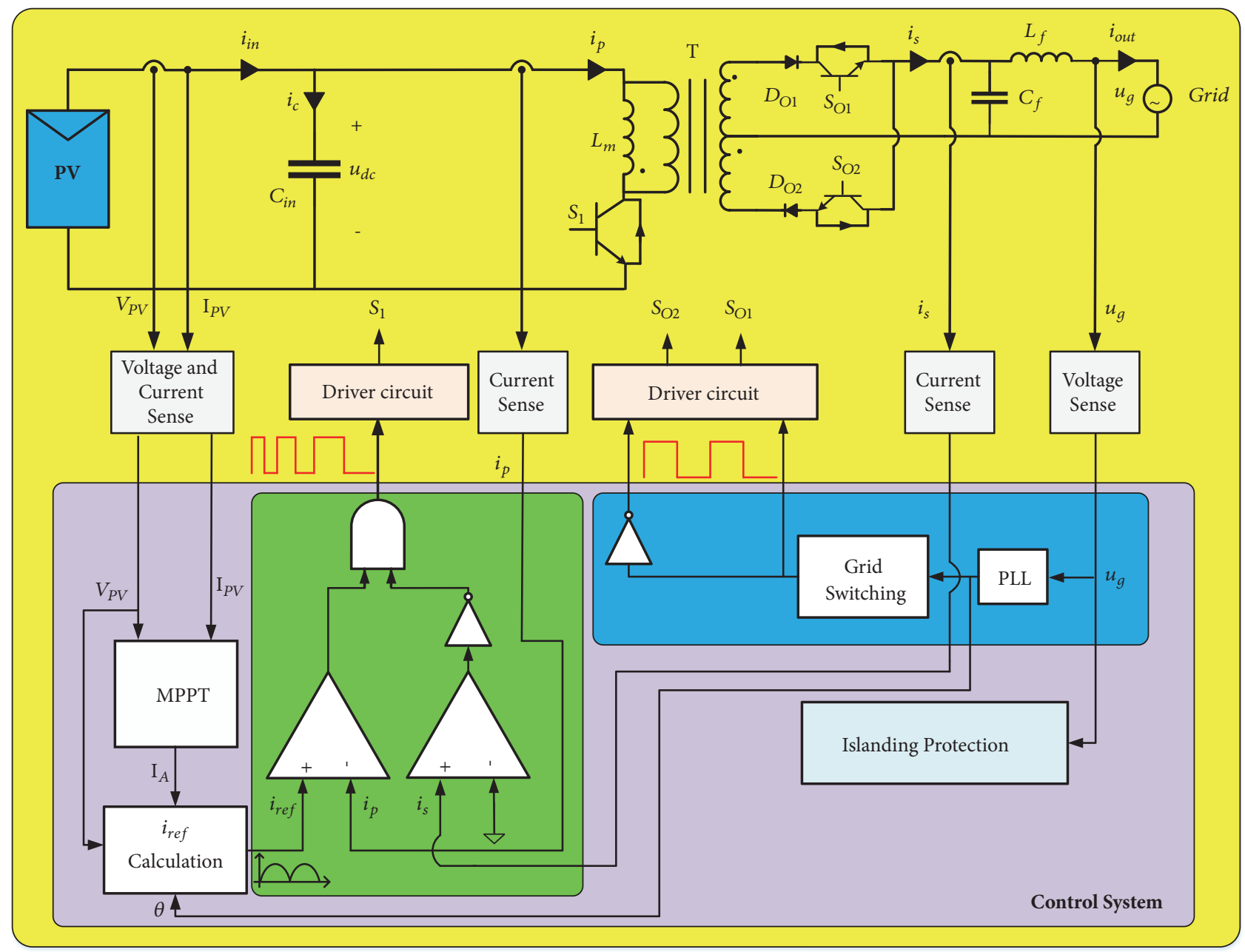

FIGURE 7: Control scheme of the flyback microinverter at BCM condition.

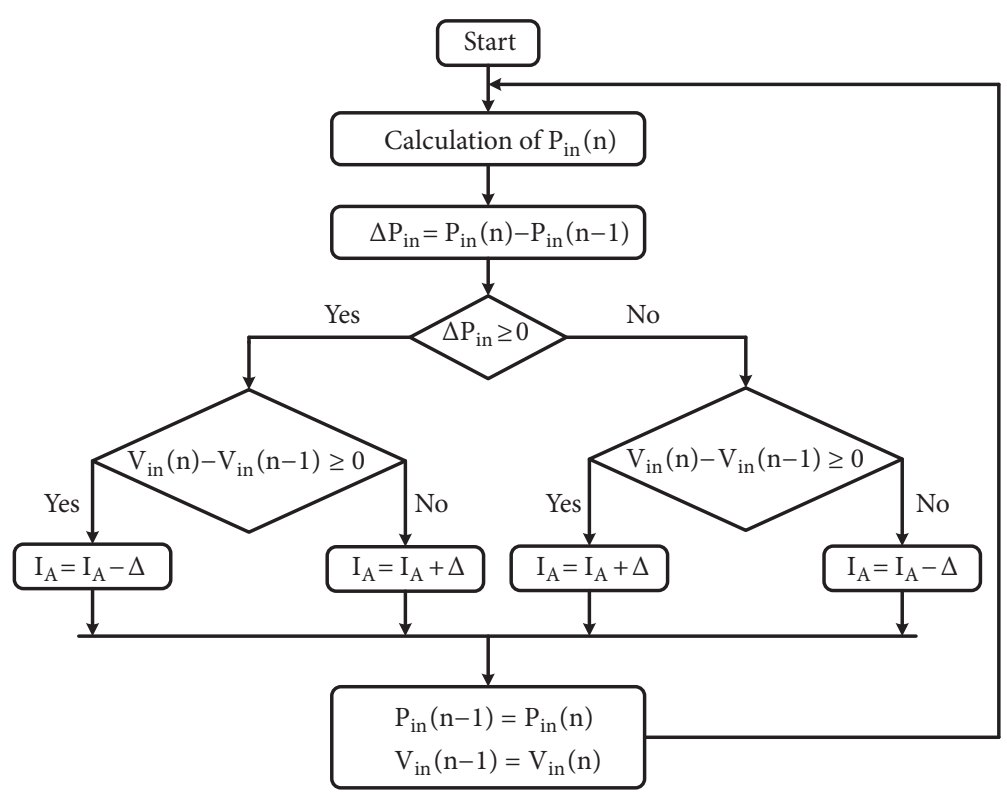

FIGURE 8: Diagram of the MPPT control based on the P\&O method. 

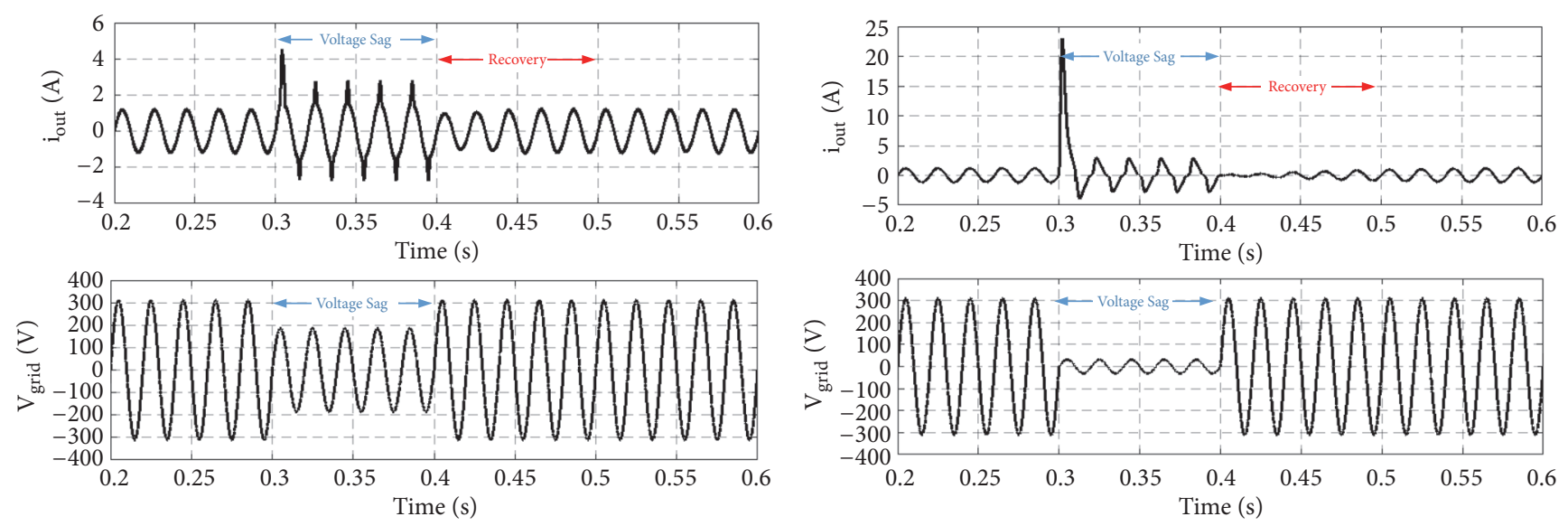

(a)

(b)

FIGURE 9: The output current and voltage of the flyback inverter at DCM condition under voltage drop. (a) Grid voltage falls to 0.6 p.u. (b) Grid voltage falls to 0.1 p.u.

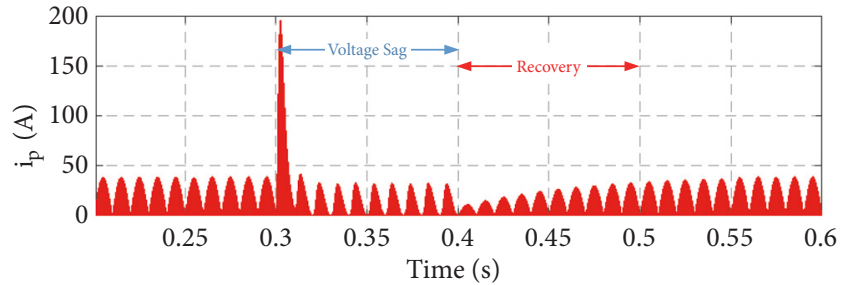

FIGURE 10: The primary current of the flyback inverter at DCM condition while grid voltage falls to 0.1 p.u.
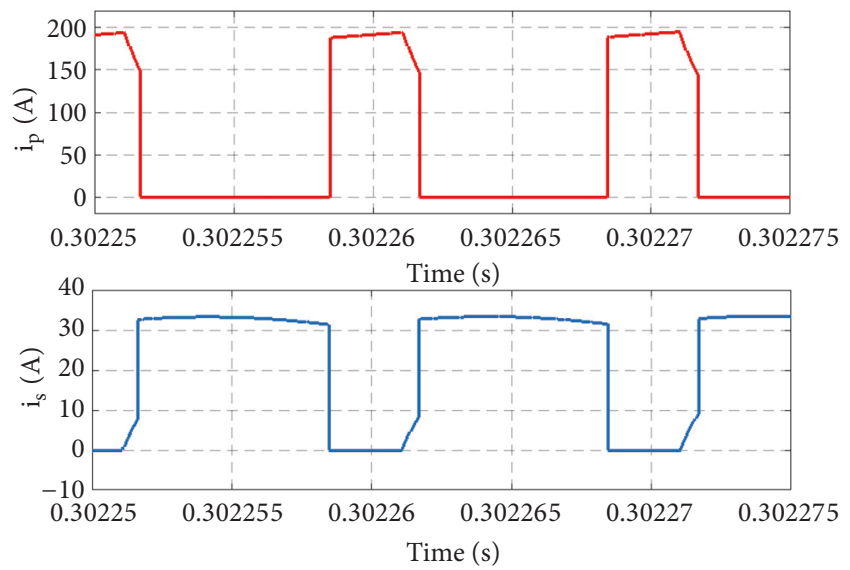

FIGURE 11: Details of the primary and secondary currents of the flyback inverter at DCM condition while grid voltage falls to $0.1 \mathrm{p}$.u.

THD and amplitude of the output and the primary currents increase significantly, which is very detrimental for the microinverter. In real case, before the current exceeds the critical value, the protection system operates and the inverter is disconnected from the grid. Hence, a flyback converter in DCM operation cannot support the LVRT capability in normal condition. In addition, as shown in Figure 9(b), the output current at the beginning and end of each half line cycle is also very high; hence, the hybrid DCM-BCM operation method which is presented in $[36,37]$ cannot support the LVRT capability in normal condition since this method uses DCM operation at the beginning and end of each half line cycle.

The output current of the flyback inverter and the grid voltage under $\mathrm{BCM}$ operation with the previous grid faults are presented in Figure 12. According to Figure 12, the amplitude of the output current is not high during the voltage sag and the inverter can tolerate this current for a short transient time. The primary current of the flyback inverter in grid period is presented in Figure 13. As presented in this figure, the output current does not rise too much since the primary reference current is limited by the value specified in the MPPT system. Also, the details of the primary and secondary currents of the flyback's transformer during voltage fault are shown in Figure 14. It can be observed that the operation of the flyback inverter remains under BCM during voltage fault. From the aforementioned results, it can be concluded that, in voltage sag duration, the flyback inverter under BCM operation can stay connected to the grid and support the LVRT capability.

Figure 15 shows the amplitude and THD of the output current of the flyback inverter at BCM condition for different voltage sags. According to this figure, decrease of the grid voltage will cause the THD and amplitude of the output current to increase. The THD of the output current during deep voltage sag (voltage drops to 0.1 p.u.) is about $6.8 \%$. The harmonic spectrum of the output current is illustrated in Figure 16, which verifies that the harmonic components are in appropriate range even during deep voltage sags. The THD analysis is missing in $[19-22,25,26,41]$ and from their provided results, it seems that the THD is high during voltage sag.

The V-I and P-V curves of the input PV panel with the maximum power of $200 \mathrm{~W}$ are depicted in Figure 17. Also, the power, voltage, and current of the PV panel during the normal and fault conditions are presented in Figure 18. Because of the fact that the grid voltage is dropped, the power of $\mathrm{PV}$ 

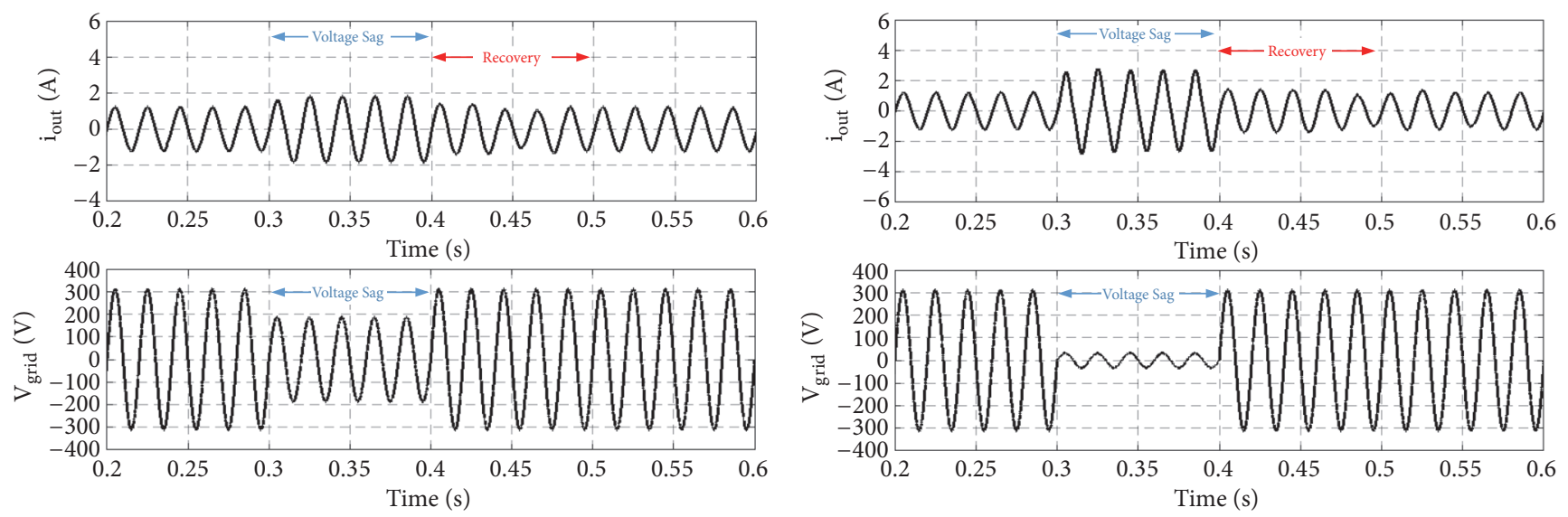

(a)

(b)

FIGURE 12: The output current and voltage of the flyback inverter at BCM condition under voltage drop. (a) Grid Voltage falls to 0.6 p.u. (b) Grid voltage falls to 0.1 p.u.

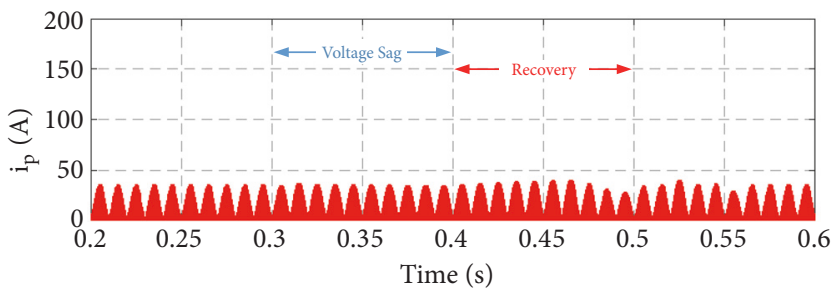

FIGURE 13: The primary current of the flyback inverter at BCM condition while the grid voltage falls to 0.1 p.u.
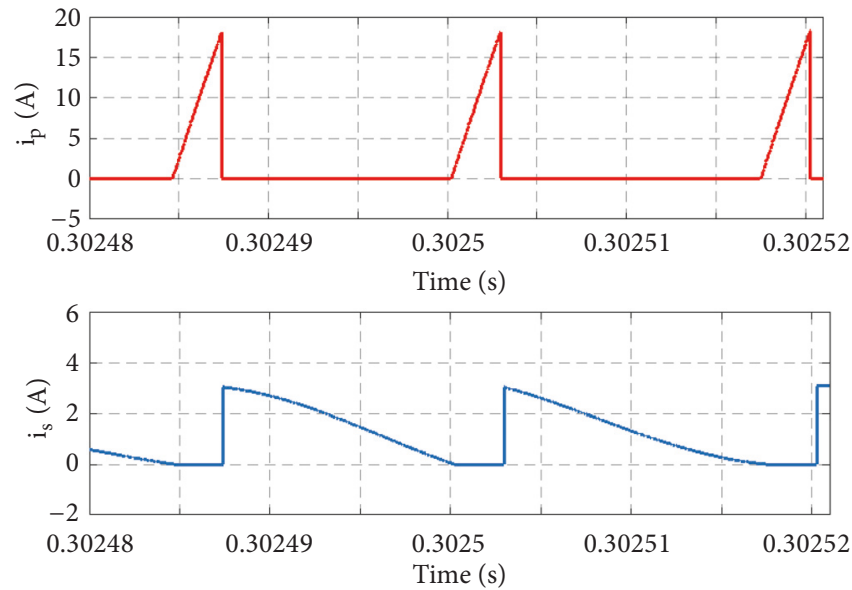

FIGURE 14: Details of the primary and secondary currents of the flyback inverter at BCM condition while grid voltage falls to 0.1 p.u.

panel reduces in the duration of the voltage sag. Also, the system returns to its normal operation and tries to achieve the maximum power point of the PV panel as soon as the fault is cleared. Nonetheless, as it can be observed from Figure 18, it may take some time due to MPPT process.

According to the presented simulation results, the flyback microinverter at BCM condition can provide LVRT capability. They confirm that, even under a deep voltage drop, the mode of the flyback inverter remains at BCM condition and the inverter contributes to helping the grid voltage and frequency stay stable during the grid faults.

\section{Conclusion}

Because of the fact that the microinverters have many merits compared to the conventional centralized architecture in DG applications, they will be a significant part of the photovoltaic systems at the urban low-voltage networks in the future. Hence, they should provide LVRT capability to enhance the grid reliability and stability.

Among various single-stage and two-stage inverters, the flyback inverter is widely used in microinverter applications because of its unique characteristics. Hence, in this paper, the 


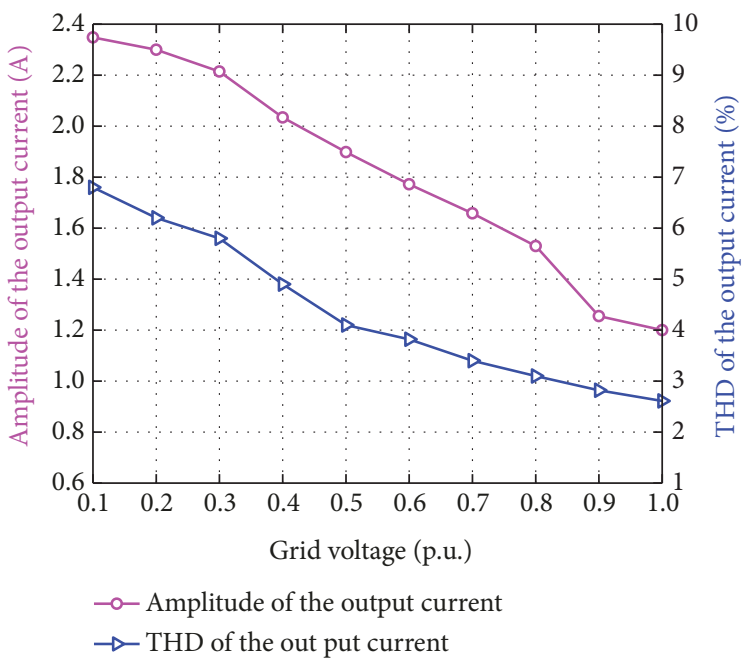

FIGURE 15: Amplitude and THD of the output current for different voltage sags.

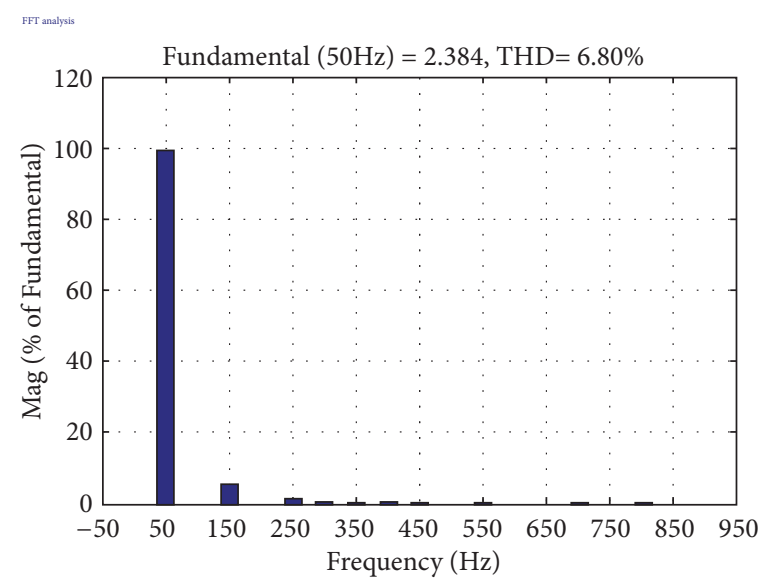

FIGURE 16: Harmonic spectrum of the output current under BCM operation while the grid voltage falls to 0.1 p.u.
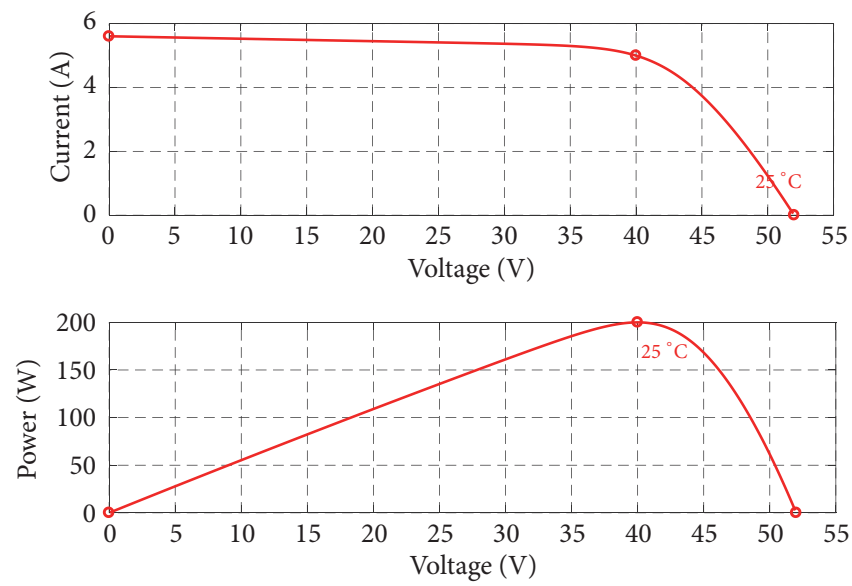

FIGURE 17: V-I and P-V curves of the PV panel. 


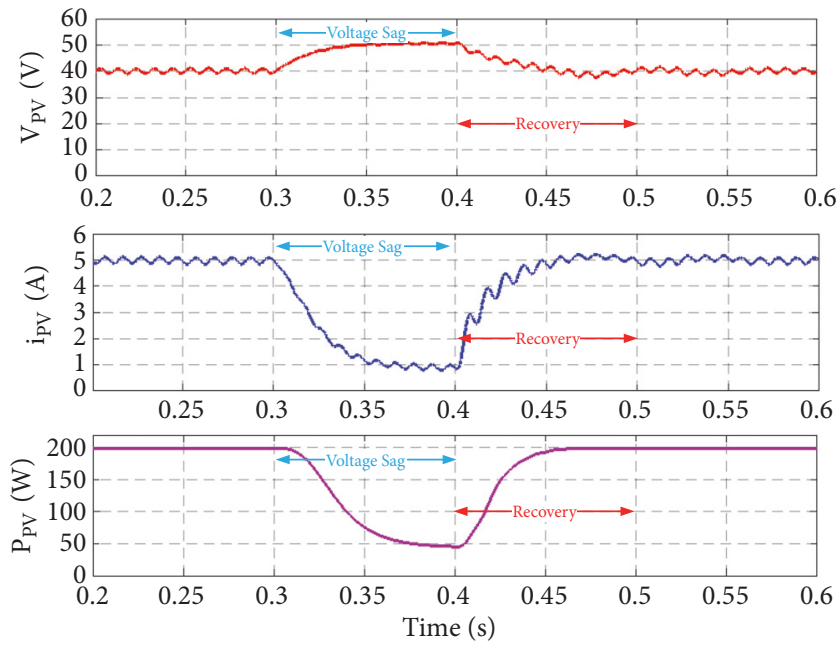

FIGURE 18: Simulation results of the MPPT control during LVRT.

flyback inverter is investigated to support the LVRT capability in order to map the future challenges. The steady-state operation of the flyback microinverter under grid voltage rise and drop conditions at BCM, DCM, and hybrid operations is investigated. It is found that the flyback inverter can provide LVRT capability automatically without using any additional control branches and any limitations in components design of the inverter if it operates at BCM condition. The control system of the flyback inverter at BCM condition is almost simple since it only needs an open-loop control technique. Therefore, the flyback inverter at BCM operation does not require any extra cost to provide the LVRT capability. This effect can enhance the demand of the flyback inverter for microinverter applications. The simulation results are provided to validate the theoretical analysis and the THD comparison proves that the THD of the output current is in appropriate range for various voltage sags when the flyback inverter operates at BCM condition.

\section{Data Availability}

The data used to support the findings of this study are available from the corresponding author upon request.

\section{Conflicts of Interest}

The authors declare that they have no conflicts of interest.

\section{References}

[1] Y. Hu, Y. Du, W. Xiao, S. Finney, and W. Cao, "DC-link voltage control strategy for reducing capacitance and total harmonic distortion in single-phase grid-connected photovoltaic inverters," IET Power Electronics, vol. 8, no. 8, pp. 1386-1393, 2015.

[2] S. A. Ansari and J. S. Moghani, "A novel high voltage gain non-coupled inductor SEPIC converter," IEEE Transactions on Industrial Electronics, 2018.

[3] Q. Li and P. Wolfs, "A review of the single phase photovoltaic module integrated converter topologies with three different DC link configurations," IEEE Transactions on Power Electronics, vol. 23, no. 3, pp. 1320-1333, 2008.

[4] R. K. Surapaneni, D. B. Yelaverthi, and A. K. Rathore, "Cycloconverter-based double-ended microinverter topologies for solar photovoltaic AC module," IEEE Journal of Emerging and Selected Topics in Power Electronics, vol. 4, no. 4, pp. 13541361, 2016.

[5] W. Yu, C. Hutchens, J.-S. Lai et al., "High efficiency converter with charge pump and coupled inductor for wide input photovoltaic AC module applications," in Proceedings of the 2009 IEEE Energy Conversion Congress and Exposition, ECCE 2009, pp. 3895-3900, IEEE, September 2009.

[6] H. Hu, S. Harb, N. Kutkut, I. Batarseh, and Z. J. Shen, "A review of power decoupling techniques for microinverters with three different decoupling capacitor locations in PV systems," IEEE Transactions on Power Electronics, vol. 28, no. 6, pp. 2711-2726, 2013.

[7] A. Yazdani and P. P. Dash, "A control methodology and characterization of dynamics for a photovoltaic (PV) system interfaced with a distribution network," IEEE Transactions on Power Delivery, vol. 24, no. 3, pp. 1538-1551, 2009.

[8] F. Iov, A. D. Hansen, P. E. S, and N. A. Cutululis, Mapping of grid faults and grid codes, Risø National Laboratory 8755036228, 2007.

[9] G. M. Saeedul Islam, A. Al-Durra, S. M. Muyeen, and J. Tamura, "Low voltage ride through capability enhancement of grid connected large scale photovoltaic system," in Proceedings of the 37th Annual Conference of the IEEE Industrial Electronics Society, IECON 2011, pp. 884-889, IEEE, Australia, November 2011.

[10] A. Marinopoulos, F. Papandrea, M. Reza, S. Norrga, F. Spertino, and R. Napoli, "Grid integration aspects of large solar PV installations: LVRT capability and reactive power/voltage support requirements," in Proceedings of the 2011 IEEE PES Trondheim PowerTech: The Power of Technology for a Sustainable Society, POWERTECH 2011, IEEE, Norway, June 2011.

[11] M. Mirhosseini, J. Pou, and V. G. Agelidis, "Single- and twostage inverter-based grid-connected photovoltaic power plants with ride-through capability under grid faults," IEEE Transactions on Sustainable Energy, vol. 6, no. 3, pp. 1150-1159, 2015. 
[12] C. Photong, C. Klumpner, and P. Wheeler, "A current source inverter with series connected AC capacitors for photovoltaic application with grid fault ride through capability," in Proceedings of the 35th Annual Conference of the IEEE Industrial Electronics Society, IECON 2009, pp. 390-396, IEEE, Portugal, November 2009.

[13] I. I. Perpinias, N. P. Papanikolaou, and E. C. Tatakis, "Optimum design of low-voltage distributed photovoltaic systems oriented to enhanced fault ride through capability," IET Generation, Transmission \& Distribution, vol. 9, no. 10, pp. 903-910, 2015.

[14] F. Yang, L. Yang, and X. Ma, "An advanced control strategy of PV system for low-voltage ride-through capability enhancement," Solar Energy, vol. 109, pp. 24-35, 2014.

[15] M. Tsili and S. Papathanassiou, "A review of grid code technical requirements for wind farms," IET Renewable Power Generation, vol. 3, no. 3, pp. 308-332, 2009.

[16] C. Abbey and G. Joos, "Effect of low voltage ride through (LVRT) characteristic on voltage stability," in Proceedings of the 2005 IEEE Power Engineering Society General Meeting, pp. 19011907, IEEE, June 2005.

[17] B. M. Buchholz, Z. A. Styczynski, and W. Winter, "Dynamic simulation of renewable energy sources and requirements on fault ride through behavior," in Proceedings of the 2006 IEEE Power Engineering Society General Meeting, PES, 7 pages, IEEE, Canada, June 2006.

[18] M. Mohammadi, J. S. Moghani, S. A. Ansari, J. Milimonfared, and A. Dehbashi, "Fuzzy logic based sensorless soft starter for constant frequency wind power plants," in Proceedings of the 9th Annual International Power Electronics, Drive Systems, and Technologies Conference, PEDSTC 2018, pp. 538-543, IEEE, Iran, February 2018.

[19] Y. Yang, F. Blaabjerg, and Z. Zou, "Benchmarking of grid fault modes in single-phase grid-connected photovoltaic systems," IEEE Transactions on Industry Applications, vol. 49, no. 5, pp. 2167-2176, 2013.

[20] Y. Yang and F. Blaabjerg, "Low-voltage ride-through capability of a single-stage single-phase photovoltaic system connected to the low-voltage grid," International Journal of Photoenergy, vol. 2013, Article ID 257487, 9 pages, 2013.

[21] Y. Yang, F. Blaabjerg, and H. Wang, "Low-voltage ride-through of single-phase transformerless photovoltaic inverters," IEEE Transactions on Industry Applications, vol. 50, no. 3, pp. 19421952, 2014.

[22] J. C. Vasquez, R. A. Mastromauro, J. M. Guerrero, and M. Liserre, "Voltage support provided by a droop-controlled multifunctional inverter," IEEE Transactions on Industrial Electronics, vol. 56, no. 11, pp. 4510-4519, 2009.

[23] N. Jaalam, N. A. Rahim, A. H. A. Bakar, and B. M. Eid, "Strategy to enhance the low-voltage ride-through in photovoltaic system during multi-mode transition," Solar Energy, vol. 153, pp. 744754, 2017.

[24] A. Q. Al-Shetwi, M. Z. Sujod, and F. Blaabjerg, "Low voltage ride-through capability control for single-stage inverter-based grid-connected photovoltaic power plant," Solar Energy, vol. 159, pp. 665-681, 2018.

[25] N. P. Papanikolaou, "Low-voltage ride-through concept in flyback inverterbased alternating current-photovoltaic modules," IET Power Electronics, vol. 6, no. 7, pp. 1436-1448, 2013.

[26] S. Öztürk and I. Çadirci, "A generalized and flexible control scheme for photovoltaic Grid-Tie microinverters," IEEE Transactions on Industry Applications, vol. 54, no. 1, pp. 505-516, 2018.
[27] S. A. Ansari, S. H. Hosseinian, and J. S. Moghani, "Lowvoltage ride-through capability of flyback inverter under BCM operation for AC module applications," in Proceedings of the 2017 IEEE Smart Grid Conference, SGC 2017, pp. 1-6, IEEE, Iran, December 2017.

[28] S. B. Kjaer, J. K. Pedersen, and F. Blaabjerg, "A review of singlephase grid-connected inverters for photovoltaic modules," IEEE Transactions on Industry Applications, vol. 41, no. 5, pp. 12921306, 2005.

[29] N. Kasa, T. Iida, and L. Chen, "Flyback inverter controlled by sensorless current MPPT for photovoltaic power system," IEEE Transactions on Industrial Electronics, vol. 52, no. 4, pp. 11451152, 2005.

[30] Z. Zhang, X.-F. He, and Y.-F. Liu, "An optimal control method for photovoltaic grid-tied-interleaved flyback microinverters to achieve high efficiency in wide load range," IEEE Transactions on Power Electronics, vol. 28, no. 11, pp. 5074-5087, 2013.

[31] S. A. Ansari, J. S. Moghani, and M. Mohammadi, "Analysis and implementation of a new zero current switching flyback inverter," International Journal of Circuit Theory and Applications, vol. 47, no. 1, pp. 103-132, 2019.

[32] D. G. Photovoltaics and E. Storage, IEEE Application Guide for IEEE Std $1547^{\mathrm{TM}}$, IEEE Standard for Interconnecting Distributed Resources with Electric Power Systems, 2009.

[33] C. E. Italiano, "Reference technical rules for connecting users to the active and passive LV distribution companies of electricity," CEI 0, vol. 21, 2011.

[34] A. C. Kyritsis, E. C. Tatakis, and N. P. Papanikolaou, "Optimum design of the current-source flyback inverter for decentralized grid-connected photovoltaic systems," IEEE Transactions on Energy Conversion, vol. 23, no. 1, pp. 281-293, 2008.

[35] Y. Li and R. Oruganti, "A low cost flyback CCM inverter for AC module application," IEEE Transactions on Power Electronics, vol. 27, no. 3, pp. 1295-1303, 2012.

[36] G. C. Christidis, A. C. Nanakos, and E. C. Tatakis, "Hybrid discontinuous/boundary conduction mode of flyback microinverter for AC-PV modules," IEEE Transactions on Power Electronics, vol. 31, no. 6, pp. 4195-4205, 2016.

[37] S. A. Ansari, A. Skandari, J. Milimonfared, and J. S. Moghani, "A new control method for an interleaved flyback inverter to achieve high efficiency and low output current THD," in Proceedings of the 9th Annual International Power Electronics, Drive Systems, and Technologies Conference, PEDSTC 2018, pp. 89-94, IEEE, Iran, February 2018.

[38] R. W. Erickson and D. Maksimovic, Fundamentals of Power Electronics, Springer Science Business Media, 2007.

[39] T. Shimizu, K. Wada, and N. Nakamura, "Flyback-type singlephase utility interactive inverter with power pulsation decoupling on the DC input for an AC photovoltaic module system," IEEE Transactions on Power Electronics, vol. 21, no. 5, pp. 12641272, 2006.

[40] B. Amrouche, M. Belhamel, and A. Guessoum, "Artificial intelligence based PO MPPT method for photovoltaic systems," Revue des Energies Renouvelables ICRESD-07 Tlemcen, pp. 11-16, 2007.

[41] H. Kobayashi, "Fault ride through requirements and measures of distributed PV systems in Japan," in Proceedings of the 2012 IEEE Power and Energy Society General Meeting, PES 2012, pp. 1-6, IEEE, July 2012. 

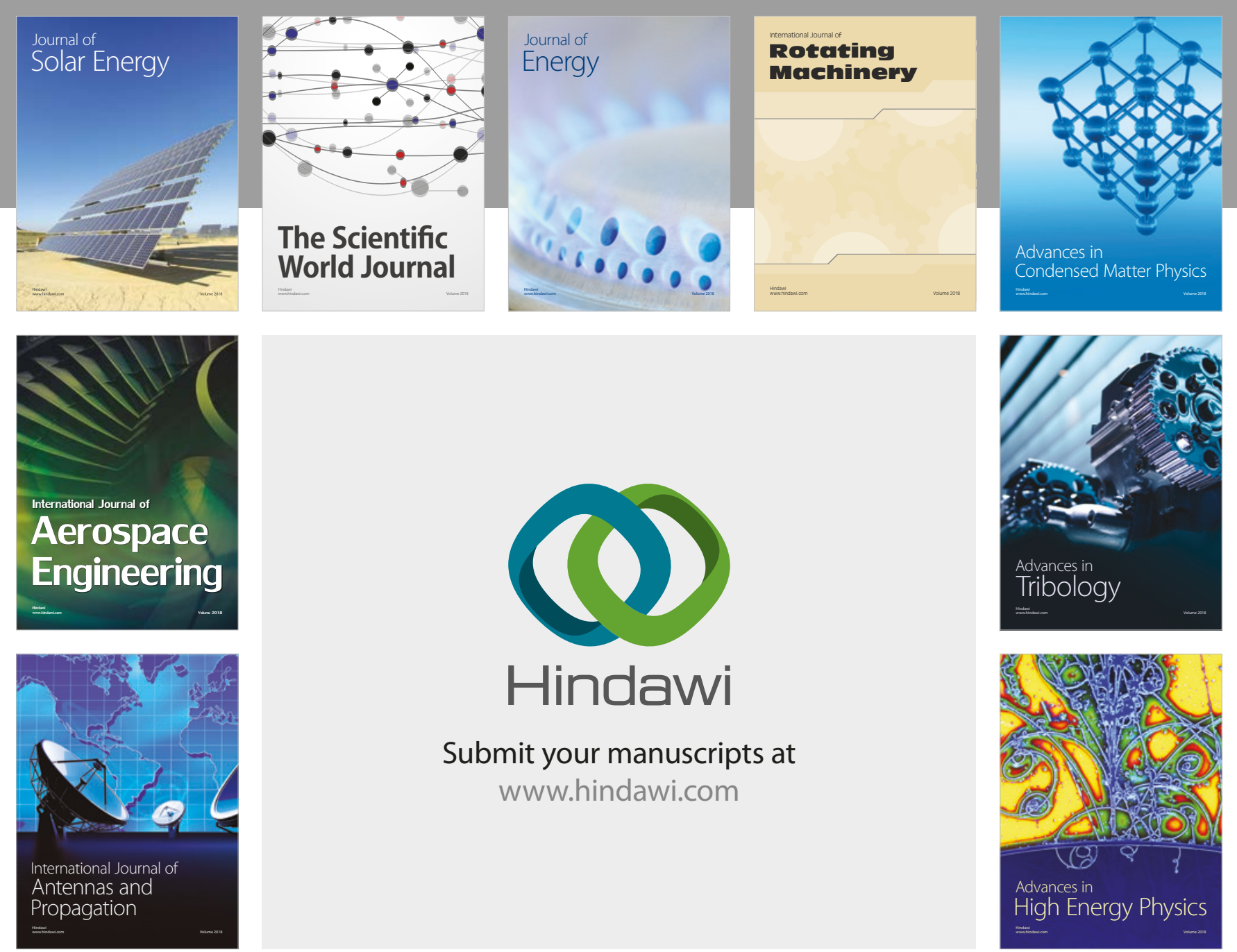

Submit your manuscripts at

www.hindawi.com
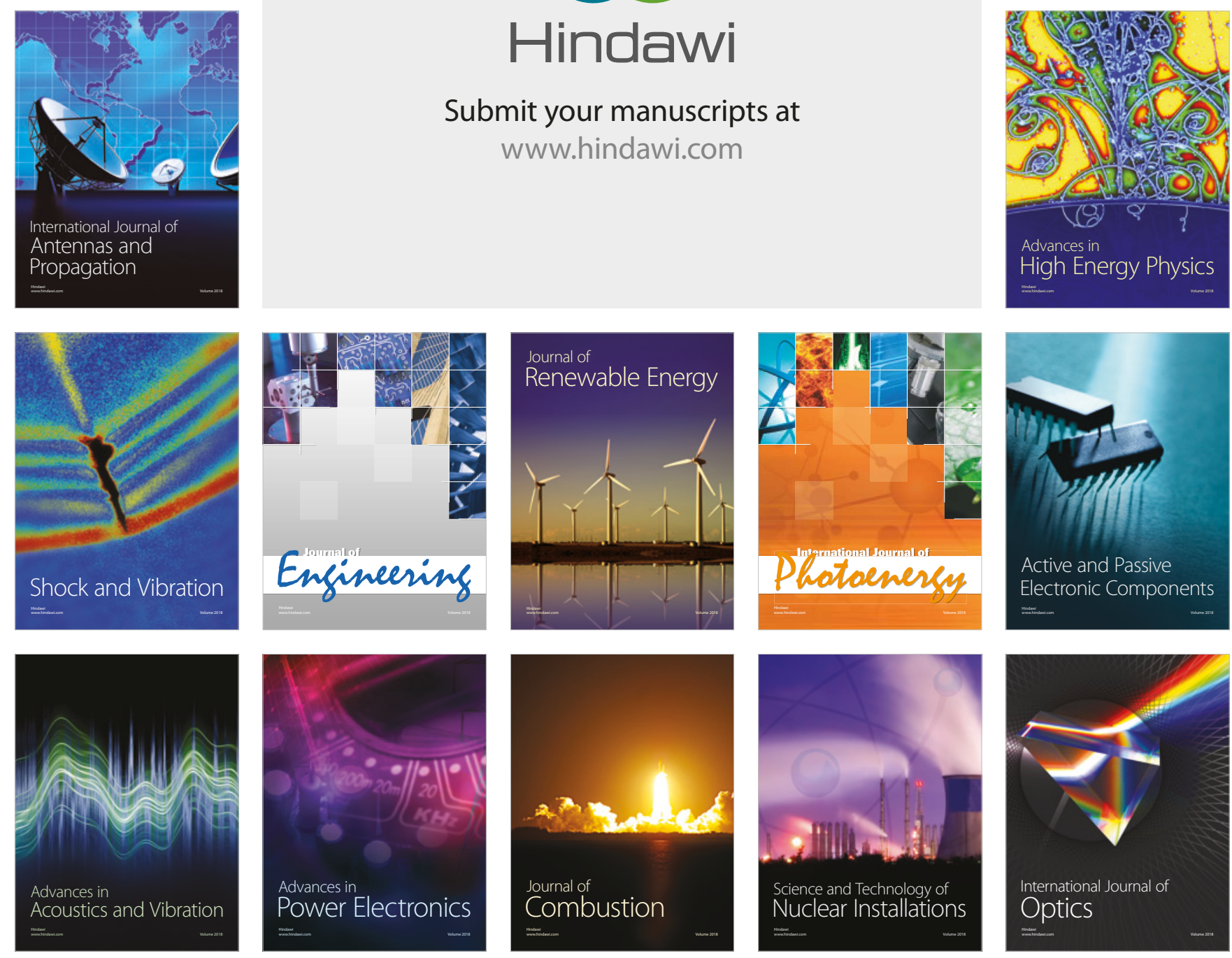